\title{
A New Testing Method to Evaluate Adhesion Strength of Ceramic Top Coat in TBCs*
}

\author{
Masakazu OKAZAKI**, Satoshi YAMAGISHI**, Masakazu OSAKABE** \\ and Hirotaka FUKANUMA*** \\ **Department of Mechanical Engineering, Nagaoka University of Technology \\ 1603-1 Kamitomioka-machi, Nagaoka, Niigata, Japan \\ E-mail:okazaki@mech.nagaokaut.ac.jp \\ *** Plasma Giken Co. Itd., Yorii, Saitama, Japan
}

\begin{abstract}
A new testing method to evaluate adhesion strength of ceramic top coat has been proposed, employing a ring shape of TBC specimen specifically designed. It was shown by the experiments that a delamination behavior of the top coat was successfully reproduced in the proposed method, associating with a buckling mode; a similar mode frequently observed in actual gas turbine components. A method to quantitatively evaluate a resistance to delamination was also introduced, based on an energy release rate criterion. The experiments demonstrated that the testing method provided reasonable adhesion strength in terms of energy criterion, that almost agreed with the values measured by other researchers employing different type of testing method. It was also shown that the present method has many advantages, compared with the traditional methods.
\end{abstract}

Key words: Adhesion Strength, New Testing Method, Thermal Barrier Coatings (TBCs), Ring Specimen, Energy Release Rate, Interface Crack, Stable Growth

\section{Introduction}

Thermally insulating ceramic coatings, known as thermal barrier coatings (TBCs) have been essential technologies to improve the performance and efficiency of advanced gas turbines in service at extremely high temperatures ${ }^{(1-6)}$. The key role of TBCs is, of course, to protect the metal substrate from high temperature oxidation and environmental attack ${ }^{(1,2)}$. In general the TBC system consists of at least three layers; ceramic top coat, bond coat and metal substrate. Each layer plays an their own part. For example, the metallic bond coat aids in the adhesion of the ceramic top coat, and also protects the substrate from hot corrosion and oxidation ${ }^{(1-5)}$. The TBC systems have been fabricated by plasma spraying techniques in many cases.

Nobody doubts that the most critical issue to reduce durability of TBCs is spallation of ceramics top coat ${ }^{(6-13)}$. Once this type of damage is realized, hot section components made of superalloy substrate may be overheated, resulting in tragic accidents. Thus, good adhesion is essential for TBCs system. Traditionally an adhesion strength was often evaluated by; e.g., ASTM C633 standard ${ }^{(7)}$. Here, after bonding the TBC specimen with a test jig through an adhesives, a tensile load is applied to undertake the decohesion of ceramic top coat. The adhesion strength is represented by the critical nominal stress at which the cohesion of top coat is broken. A simplicity is the most useful advantage of this method. However, some disadvantages have been pointed out in this method. One is that the usage of adhesives which possibly penetrates into the porous structure of top coat fabricated by plasma spraying, resulting in somewhat misleading results ${ }^{(11)}$. The second disadvantage

*Received 8 Sep., 2009 (No. 09-0498) [DOl: 10.1299/jmmp.4.345]

Copyright $@ 2010$ by JSME 
is a size effect: the adhesion strength often depends on the size of the specimen used ${ }^{(8-11)}$. This size effect is believed to be attributed to both non-uniformity in stress distribution and stress singularity especially at the edge of specimen that is an intrinsic problem so far as the TBC system consists of different kind of materials. In order to be free from the second problem, interface facture mechanics is often employed as an alternative method, where the adhesion is not expressed in terms of stress but on the basis of either an energy criteria with advance of interface crack, or a magnitude of stress singularity ${ }^{(8-13)}$. Whereas these evaluation methods are on the basis of physics, there is still too high hurdle to be used in engineering filed. One of the reasons is a complexity of the treatment. The other reason is that the geometry of specimens used there; e.g., four-point bending specimen, is far from actual three dimensional geometry of gas turbine TBCs. These force us some difficulties to convert the test results to the actual cases. Furthermore, while residual stress is known to play an important role in the adhesion strength ${ }^{(10,12)}$, there is still a question that residual stress field in actual TBC components is successfully realized in the idealized specimens.

The object of this work is to explore a new testing method to evaluate the adhesion strength of ceramic top coat used for TBCs. Special emphasis is put on so that the method is simple, but it can provide an adhesion strength on the basis of physical principle, and that the decohesion process during the test can realize the actual delamination process of top coat as much as possible.

\section{Experimental Procedure}

\subsection{Propose of a new type of specimen}

When a new testing method for adhesion strength, or resistance to decohesion of top coat in TBCs, is explored, the following requirements should be taken into account in general. The first is a simplicity of geometry of specimen used. On the contrary, the specimen is recommended to satisfy such a conflicting requirement that its geometry is reproducing the actual TBCs as much as possible. It is also required that residual or internal stress state is successfully realized in the specimen, since internal and thermal stress play an important role in the delamination process to the ceramic top coat ${ }^{(10,12)}$. From the last two requirements, a four-point bending specimen seems to be incomplete to be used. Taking account of the above conflicting requirements, a ring shape TBC specimen illustrated in Fig. 1 is proposed and explored in this work. Note that this type of specimen can simply simulate actual blade geometry with complex curvatures. In addition, the residual stress can be introduced in natural manner, because the internal or residual stress is built up in bi- or tri-axial stress state in this type of geometry. The latter is an advantage to be hardly realized, e.g. in four-point bending specimen.

The TBC specimen illustrated in Fig. 1 consists of three layers; INCONEL 738LC Nibase superalloy substrate, bond coat and top coat, where an initial defect is artificially introduced at the bond/top coat interface. Here, an $8 \mathrm{wt} . \%$ yttria partially stabilized zirconia (YSZ) (;METCO 204NS), and a CoNiCrAlY alloy(;AMDRY9951), were selected as the top and bond coat materials, respectively. The chemical compositions of these materials are given in Table 1.

The TBC specimens were prepared as follows. The first step was the spraying of bond coat alloy on the substrate, which was carried out by $100 \mu \mathrm{m}$ in thickness employing low pressure plasma spraying on the substrate, rotating the cylindrical substrate specimen. The second step was the process to introduce an initial artificial defect at the interface, to which special attentions were paid in this work. This process was as follows: at first in the second step, a local area of the bond coat surface was carefully covered with a silicon resin, KR (where KR is trademark by Shin-etsu Silicon Co. Ltd, Japan), where the covered area would be corresponding to a initial defect area at final. Then, a shot-blasting of the bond coat surface was performed, masking the resin area. The final step was the coating of ceramic 


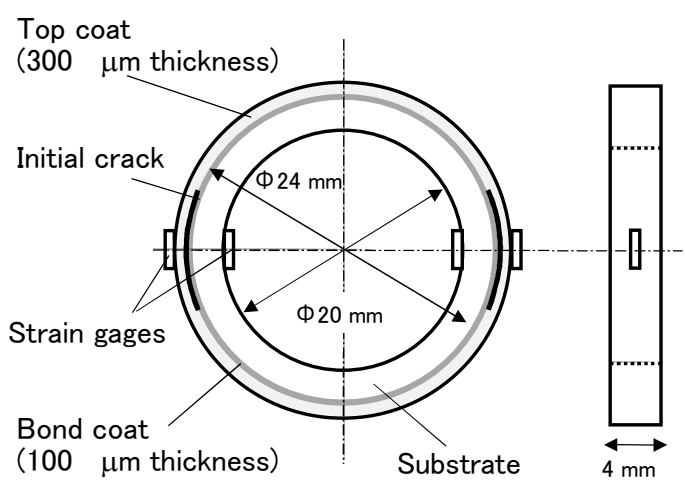

Fig. 1 Geometry of TBC specimen proposed.

Table 1 Chemical compositions to top coat, bond coat and substrate (in wt.\%).

(a) Top coating powder.

\begin{tabular}{|c|c|c|c|c|c|c|}
\hline $\mathrm{ZrO}_{2}$ & $\mathrm{Y}_{2} \mathrm{O}_{3}$ & $\mathrm{HfO}_{2}$ & $\mathrm{MgO}$ & $\mathrm{SiO}_{2}$ & $\mathrm{TiO}_{2}$ & $\mathrm{CaO}$ \\
\hline 90.5 & 7.5 & 1.6 & $<0.01$ & 0.04 & 0.11 & 0.02 \\
\hline
\end{tabular}

(b) Bond coating powder.

\begin{tabular}{|c|c|c|c|c|}
\hline $\mathrm{Co}$ & $\mathrm{Ni}$ & $\mathrm{Cr}$ & $\mathrm{Al}$ & $\mathrm{Y}$ \\
\hline 38 & 32 & 21 & 8 & 0.5 \\
\hline
\end{tabular}

(c) Substrate alloy.

\begin{tabular}{|c|c|c|c|c|c|c|c|c|c|c|c|}
\hline $\mathrm{C}$ & $\mathrm{Si}$ & $\mathrm{Mn}$ & $\mathrm{Cr}$ & $\mathrm{Co}$ & $\mathrm{Mo}$ & $\mathrm{W}$ & $\mathrm{Cu}$ & $\mathrm{Ta}$ & $\mathrm{Ti}$ & $\mathrm{Al}$ & $\mathrm{Ni}$ \\
\hline 0.09 & 0.04 & - & 16.0 & 8.14 & 1.65 & 2.58 & - & 1.72 & - & 3.57 & Bal. \\
\hline
\end{tabular}

top coat by $300 \mu \mathrm{m}$ in thickness by atmospheric plasma spraying. On the way of the final step, an initial notch was formed at the bond/top coat interface, by such a principle that since the ignition temperature of the resin is almost $250^{\circ} \mathrm{C}$, it would almost disappear during the spraying, resulting in a source of artificial defect. Figure 2 displays morphology around the initial defect tip at the interface, which shows that the initial notch has been successfully introduced. The length of initial notch was experimental variables in this work: it was from zero to $7 \mathrm{~mm}$ in total. These fabrication processes were carefully managed by Plasma Giken Co. Ltd.

\subsection{Testing method}

In general adhesion tests an external load is applied to the specimen to accelerate the

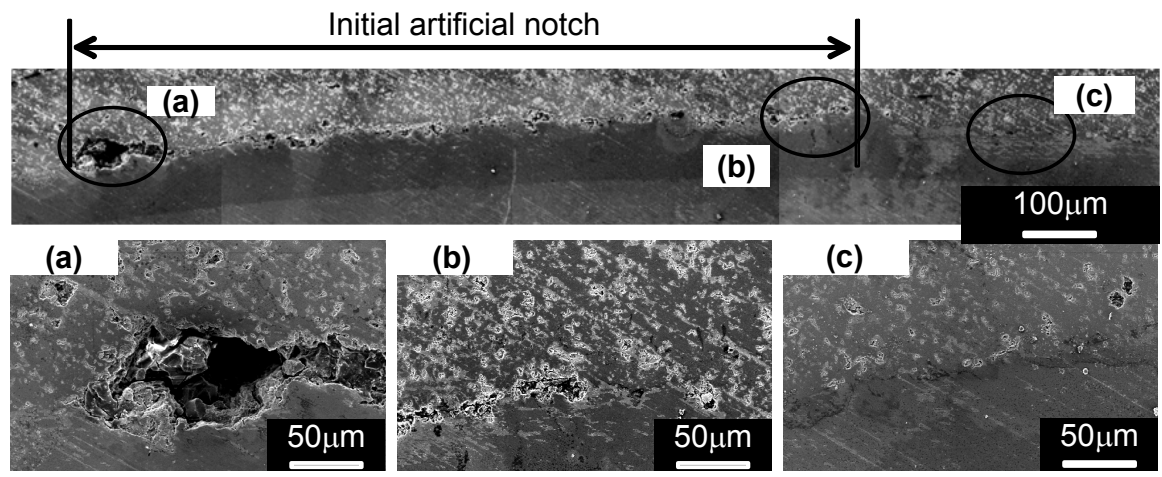

Fig. 2 Morphology of initial artificial notch introduced at top coat/bond coat interface. 


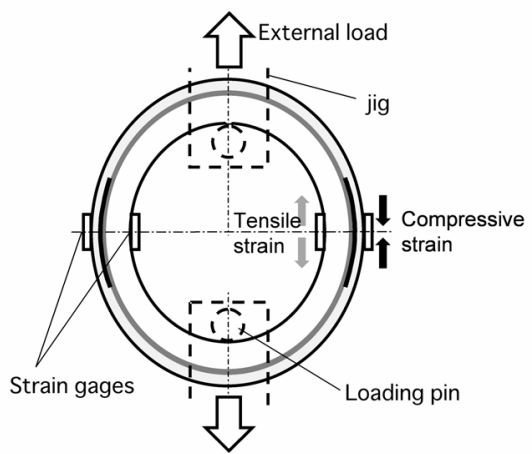

Fig. 3 Loading method to induce a delamination of top coat.

delamination of coatings or film. It is needless to say, the better, the more similarly to the actual failure mode the decohesive process is realized in the test. It may be a buckling mode to be concerned in this work, because the decohesion of top coat of TBCs is known to be taken place with buckling mode in many cases ${ }^{(8,10)}$.

Taking account these situations into consideration, a "buckling-induced delamination test method" of top coat has been explored and proposed in this work, where a tensile load was applied to the ring specimen through two loading pins so that a delamination of top coat was induced: see Fig. 3. Here, when tensile load is applied to the specimen, a compressive stress is built-up at the outer surface at " 3 and 9 O'clock" in the specimen, which may induce a buckling of the top coat. An artificial notch introduced there must be a nucleation site for the delamination of top coat. The magnitude of compressive stress depends on the geometry of specimen employed, and hence, the specimen geometry is a factor to be designed. Note such an advantage in this test method that the method is free from a problem of direct contact of loading pin(s) with the top coat. This merit is too hard to be realized in the traditional methods. For example, ASTM C633 needs adhesives to bond top coat with test jig ${ }^{(7)}$, and in the usual four-point bending test it is necessary to contact two loading pins directly with top coat when compressive stress is built up in the top coat.

On conducting the actual buckling-induced delamination tests, an external load was applied to the specimen through two loading pins under a displacement-controlled condition by means of a closed-loop servo-electro hydraulic machine (see Fig. 3), where the displacement rate was $3.3 \times 10^{-7} \mathrm{~m} / \mathrm{sec}$. $(0.02 \mathrm{~mm} / \mathrm{min}$.). In the test, four strain gauges were pasted on the surface of TBC specimens, in order to observe how the delamination and any other types of failures evolve. The sites adhered were on both the inside and outer surfaces of the specimen at "3 and 9 O'clock" in this work. At the same time, the specimen was continuously monitored by a CCD camera and a traveling microscope.

\section{Results and Discussion}

\subsection{Progress of delamination of top coat}

Figure 4 summarizes what happened during the buckling-induced delamination test proposed in this work. Figure 4 (a) reveals the change of top coat strain (measured at "3 or 9 O'clock" point) with the loading point displacement, comparing with that of the bond coat/top coat interface. Here the latter strain was measured by means of an other specimen without top coat, and these two curves are illustrated on the same loading point displacement in Fig. 4 (a). Figure 4(b), on the other hand, expresses the changing behavior of interface crack length measured by a traveling microscope.

Many noteworthy phenomena are found from Fig. 4. First of all, when the loading started, the strains both at the top coat surface and at the bond/top coat interface has begun 
(a)

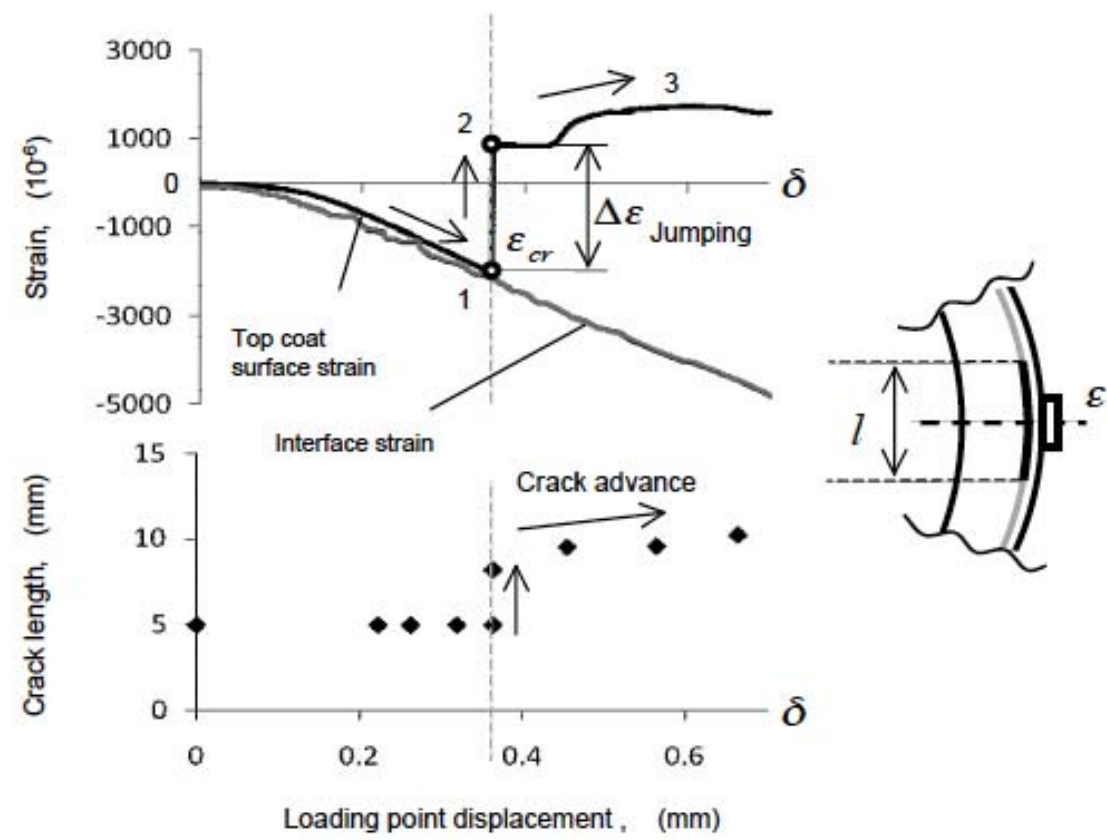

Fig.4 Some typical events observed in the proposed method. (a) Change of strain on top coat, (b) Change of interface crack length.

to increase monotonically toward compression side (: from Points 0 to 1 in Fig. 4(a)), according to similar manner, as expected in Sec. 2. The most important event happened when the external load reached a critical Point 1 , or a critical strain denoted by $\varepsilon_{c r}$ : i.e., at this point the strain on top coat surface suddenly jumped by an amount of $\Delta \varepsilon$ (from Points 1 to 2 in Fig. 4), while the strain at the bond coat /top coat interface monotonically increased. Here, the curve of interface strain was monitored by the specimen without top coat, and it is illustrated corresponding to the same loading point displacement as the TBC specimen. It is important to note that the top coat strain skipped from in compression to in tension at that point, strongly suggesting that the top coat would be buckled, as shown later. When the load was increased after the Point 2, the top coat strain increased gradually in tension, associating with some fluctuations (from Points 2 to 3 in Fig. 4(a)). Even during this period, the interface strain was still in compression.

Figure 5 reveals what happened at a critical point 1 . It is clear that an interface crack advanced after this point along the prior interface (compare Figs. 5(a) with 5(b)). With increasing of loading point displacement, the interface crack exhibited a stable growth behavior, as shown in Fig. 5(c) (this process corresponds to Points 2 to 3 in Fig. 4(a)). Here, the crack still propagated along the top-bond coat interface. Strictly speaking, however, the crack propagation was not just along but beneath the interface, as often the cases in many references as well ${ }^{(11,13)}$. The interface crack length measured during this period was plotted by data points in Fig. 4(b). It is worthy to compare the change of crack length with the strain jumping. When the loading point displacement increased moreover (between Points 2 and 3), other type of failure mode also appeared in some cases: the interface cracks propagated to the inside of top coat, resulting in the rupture of top coat and the spalling out as fragments (Fig.5 (d)). A frequency of the last failure mode emergence seemed to be depending on the initial defect size.

Summarizing these observations, it is reasonable to postulate that in the proposed testing method the failure might advance, accompanying with the following process and mechanism (see Fig. 6): when the compressive strain built up in the top coat by the external 


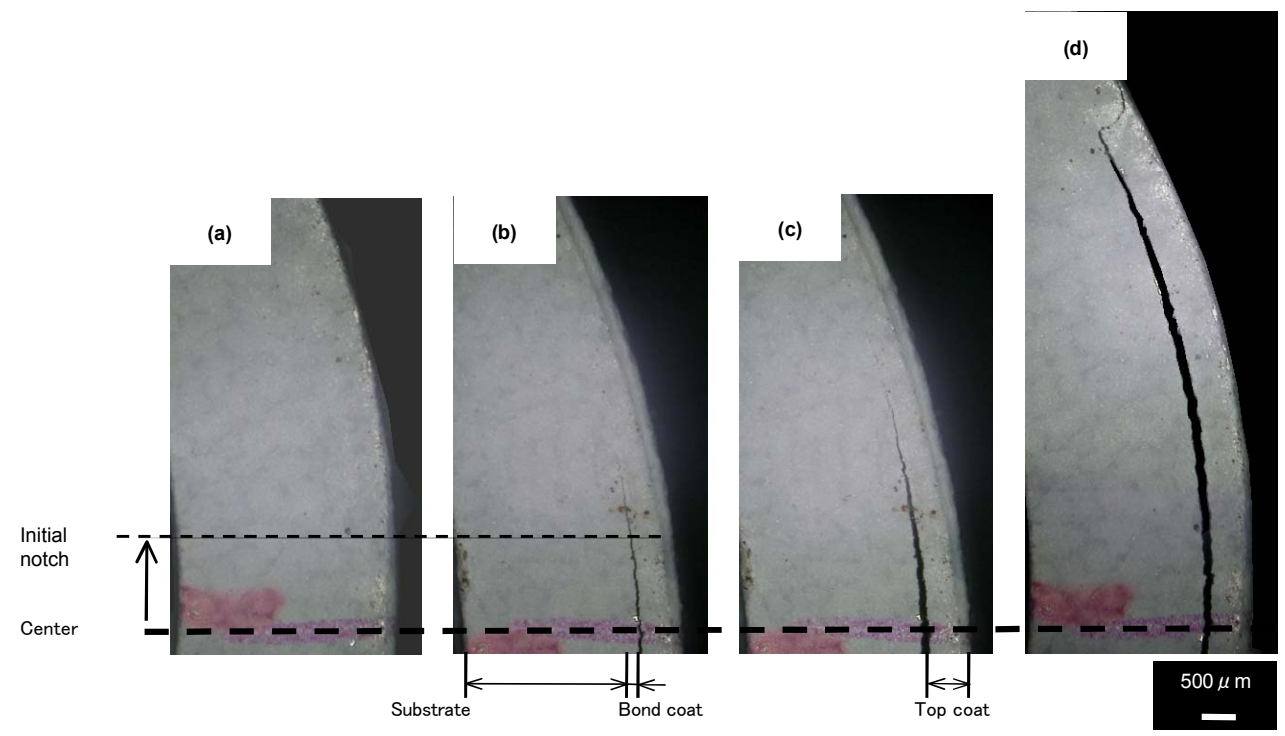

Fig. 5 Changes of interface crack morphologies with loading. (a) Initial morphology, (b) Just after the strain jumping, (c) Stable growth after the critical point. (d) Rupture of top coat appearing in some cases.

\section{Remote compressive strain}

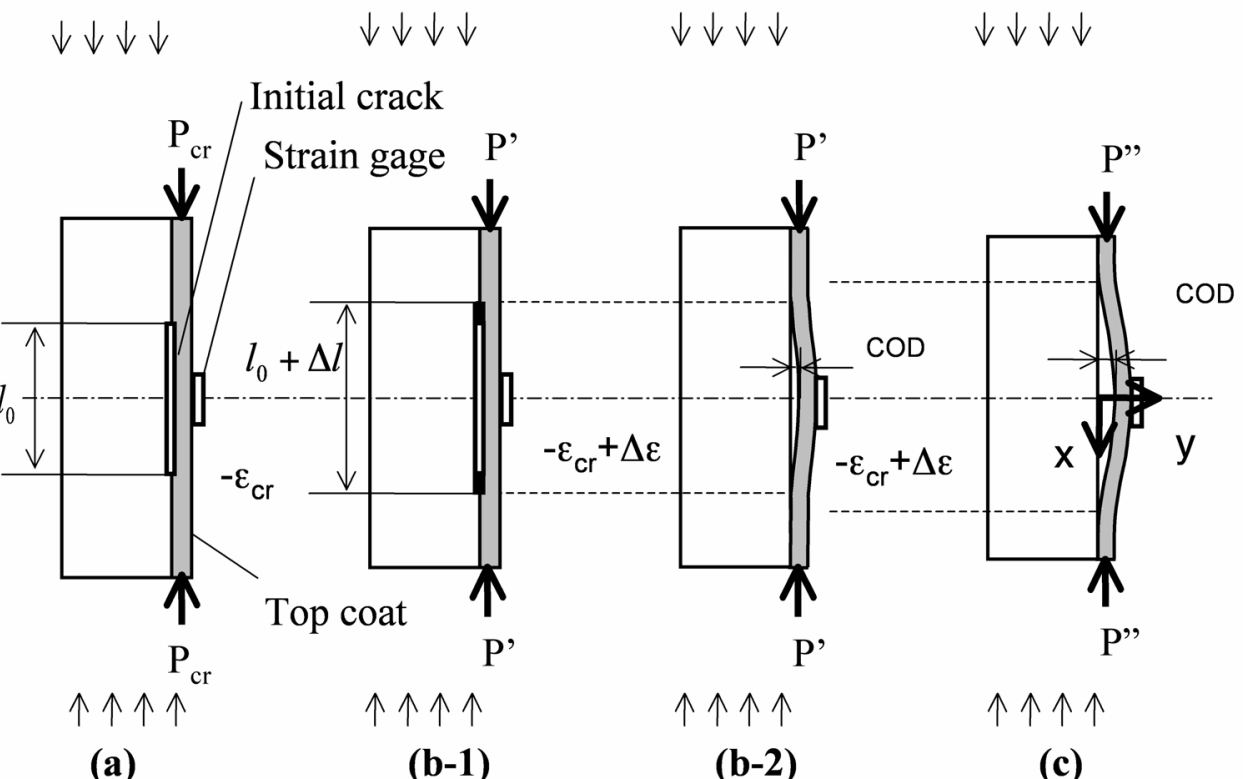

Fig. 6 Spalling process of top coat and the mechanisms during the testing method proposed.

loading arrived at a critical strain, $\varepsilon_{c \mathrm{cr}}$ (Fig. 6(a)), the top coat might be buckled (:Fig. 6(b-2). At the same time the interface (or delamination) crack advanced (: Fig. 6(b-1), followed by a stable crack propagation near the prior interface (:Fig. 6(c)). Here, it is worthy to note that once the top coat is buckled, the axial load in the top coat might be relaxed from $P_{\text {cr }(l)}$ to $P_{\left({ }^{\prime}+\Delta l\right)}^{\prime}$; refer to the process from Fig. 6(a) to 6(b). Because these processes agree well with the actual spalling process observed ${ }^{(8-10)}$, the proposed method can successfully reproduce from the initiation to the subsequent growth behavior of interface crack in TBCs, as expected in Sec. 2. 
In order to get more quantitative understanding on the decohesion process and its resistance, a jump of the interface crack opening displacement, $C O D$, was measured at the critical point; Point 2 in Fig. 4(a)), where the COD was defined as illustrated in Fig. 6(b)-2, and its value was measured at the center of post buckled top coat. The measurement results are summarized in Table 2, together with the other important values; $\Delta \varepsilon$ and $\varepsilon_{c r}$. Note that while the value of $\varepsilon_{c r}$ given in Table 2 are positive, they were in compression. For the purpose of comparison the results observed in the other TBC system (with SUS 304 stainless steel substrate) are also picked up in Table 2. These results will be used to evaluate the adhesion strength, which will be documented later.

\subsection{Evaluation of energy release rate with delamination}

Traditionally adhesion strength has been often evaluated according to the ASTM C633 standard, where the adhesion strength is expressed by the critical nominal stress at which the decohesion of top coat is taken place. While this method is simple, there are some disadvantages in this method. One of them is a size effect in strength: the adhesion strength changes, depending on the size of specimen used ${ }^{(8-11)}$. This size effect is believed to be attributed to non-uniform stress state during the test and the stress singularity especially at the edge of specimen. In order to be free from this problem, a concept of energy release rate has been studied to express the adhesion strength ${ }^{(8-13)}$. Since the failure was taken place along the top-bond coat interface in this work, this type of concept would be applicable. Since this treatment is based on physics, it is easy to merge into the treatment based on interface facture mechanics.

According to the failure process and mechanisms illustrated in Figs. 4-6, let's consider a change in strain energy from Fig. 6(a) to (b-2) which corresponds to the energy necessitated for advance of interface crack. In the present work, on the other hand, it is reasonable to assume that stiffness of substrate is high enough, compared with that of top coat; thus, for the purpose of energy change calculation it is adequate to consider a change in stored strain energy in the top coat before/after the advance of delamination. Now let's denote the strain energy stored in the top coat to be concerned before/after the advance of delamination by $\phi_{\text {before }}$ and $\phi_{\text {after }}$, respectively. The change of strain energy are defined by

$$
\Delta \phi=\phi_{\text {before }}-\phi_{\text {after }}
$$

Equation (1) is an important parameter to represent the delamination behavior.

It is the section of top coat between $-(l+\Delta l) / \leqq x \leqq(l+\Delta l) / 2$ (where $x$ is the coordinate axis as shown in Fig. 6(c)) that should be concerned when we calculate $\phi_{\text {before }}$ and $\phi_{\text {after }}$, because the most significant changes; both the buckling of top coat and the relaxation in axial load, are taken place exclusively there. Thus, $\phi_{\text {before }}$ is approximately evaluated by

$$
\phi_{\text {before }}=(l+\Delta l) \frac{E b h}{2} \varepsilon_{c r}^{2}
$$

where $\varepsilon_{c r}$ is a critical strain just before the buckling, and $\boldsymbol{b}, \boldsymbol{h}$ and $\boldsymbol{E}$ are is thickness, width and Young's modulus of the top coat, respectively. As the top coat thickness was thin enough compared with that of substrate in this work, bending component in the top coat was neglected in Eq. (2).

As documented earlier, the top coat was delaminated, at the same time as the interface crack propagation, resulting in the relaxation of axial load from $P_{c r(l)}$ to $P_{(l+\Delta l)}^{\prime}$ (Note, $P_{(l+\Delta l)}^{\prime}$ implies, $\mathrm{P}^{\prime}$ is a function of $(l+\Delta l)$. During this process, the top coat strain was also 
jumped by an amount of $\Delta \varepsilon$ (see Figs. 4 and 6). Note that $P_{(l+\Delta l)}^{\prime}$ works as a source of bending moment for the post buckled top coat, and that $P_{(l+\Delta l)}^{\prime}, C O D$ and $\Delta \varepsilon$ are not independent variables from each other, as shown later. Employing beam theory, total strain energy stored between $-(l+\Delta l) / 2 \leqq x \leqq(l+\Delta l) / 2$ after the advance of delamination, $\phi_{\text {after, }}$ can be expressed in terms of these parameters by

$$
\left.\phi_{\text {after }}=(l+\Delta l) \frac{E b h}{2} \frac{\left(\Delta \varepsilon-\varepsilon_{c r}\right)^{2}}{\left(\frac{6 C O D}{h}-1\right)^{2}}+\frac{E b h^{3} \pi^{4}(C O D)^{2}}{12(l+\Delta l)^{3}}\right)
$$

The first and second terms in Eq. (3) correspond to strain energies promoted by axial and bending components, respectively. On deliverying Eq. (3) the shape of post buckled top was approximated by,

$$
y=\frac{C O D}{2} \cdot[1+\cos \{2 \pi x /(l+\Delta l)\}]
$$

assuming that the buckling displacement remains reasonably small ${ }^{(9)}$. Meanwhile, when we consider both the strain history from the Points 0 to 2 in Fig. 4 and the sources of strain to reach there, the value of $\left(\Delta \varepsilon-\varepsilon_{c r}\right)$ measured at $x=0$ should satisfies,

$$
\begin{aligned}
& P_{(l+\Delta l)}^{\prime}\left(\frac{C O D}{Z E}-\frac{1}{E b h}\right)=\Delta \varepsilon-\varepsilon_{c r} \\
& \varepsilon_{c r}=\frac{P_{c r(l+\Delta l)}}{E b h} \\
& Z=\frac{b h^{2}}{6}
\end{aligned}
$$

It is worth noting that at the same time Eq. (5) is an alternative expression to experimentally estimate the post buckled axial load, $P_{(l+\Delta l)}^{\prime}$ as the function of $\Delta \varepsilon, \varepsilon_{c r}$ and $C O D$.

Now, an energy release rate with an advance of interface crack per unit crack area, $G$, is derived from Eqs. (2)-(5) by

$G=\frac{\left(\phi_{\text {before }}-\phi_{\text {after }}\right)}{b \cdot \Delta l}=\frac{(l+\Delta l)}{\Delta l} \frac{E h}{2}\left\{\varepsilon_{c r}{ }^{2}-\frac{\left(\Delta \varepsilon-\varepsilon_{c r}\right)^{2}}{\left(\frac{6 \cdot C O D}{h}-1\right)^{2}}\right\}-\frac{E h^{3} \pi^{4}(C O D)^{2}}{12 \cdot \Delta l \cdot(l+\Delta l)^{3}}$

From an energy balance of the system considered, energy corresponding to Eq. (6) should be consumed to form new surface, or an advance of interface crack. $G$ for a similar case has been derived in the other form by other researchers ${ }^{(9,10)}$. Note that while the reference ${ }^{(9)}$ deals with $G$ relevant to delamination crack advance during the process in which the delamination crack grows under the post-buckled state, Eq. (6) covers the process associating with a transition from un-buckled to post-buckled state. From this point of view, Eq. (6) is expected to be a parameter involving the nucleation process for decohesion. Equation (6) will be extended near future in such a case that there is a significant residual stress in the top coat.

\subsection{Results on adhesion strength}

Based on Eq. (6) the energy release rate was evaluated at Points 2 in Fig. 4, or the critical point when the interface crack has begun to grow. The value evaluated here must correspond to the resistance to delamination, or the adhesion strength. Table 2 summarizes the results in the respective specimens, together with the values of $\Delta \varepsilon, \varepsilon_{c r}$ and $C O D$. On the 
calculation, $30 \mathrm{GPa}$ was used for the Young's modulus of top coat measured elsewhere ${ }^{(14)}$. It is seen from Table 2 that the adhesion strength was approximately 30 to $50 \mathrm{~J} / \mathrm{m}^{2}$ in the present TBCs, while it seems to be dependent a little on the initial defect size. These values almost agree with those measured by other researchers ${ }^{(13)}$. It is also interesting in Table 2 that the adhesion strength of the TBC specimen with superalloy substrate was almost comparable to that of the specimen with SUS 304 substrate. As measured elsewhere ${ }^{(14)}$, the residual stress was nearly zero in the both specimens: from -10 (in compression) to 10 (in tension) $M P a$ approximately. Thus, the insensitiveness to the substrate alloy seen in Table 2 would be relating to low and comparable residual stress in the both. However, this aspect needs further investigations more quantitatively.

As a trial, the adhesion strength was evaluated in the smooth specimens without artificial initial defects: see Table 2. It is worthy to focus that the strength evaluated here was almost comparable to that by means of the specimens with artifical notch. Although the reliability is quantitatively a little doubtful in this case (because the value of $\Delta l$ in Eq. (6) is $(l+\Delta l)$ itself there), this value hopefully corresponds to the resistance to decohesion crack nucleation itself. An alternative method to estimate a resistance to nucleation of decohesion crack is schematically introduced in Fig. 7, extending a traditional method to evaluate fracture toughness of ductile materials ${ }^{(15)}$. In Fig. 7 the resistance will be estimated by extrapolating the stable crack growth curve which are derived by following the same procedure as in this work, where a single or multiple specimen with different delamination crack length will be used. Now further investigations are on going to explore these points, and will be reported near future.

Table 2 Summary of test results.

\begin{tabular}{|c|c|c|c|c|c|}
\hline Substrate & $\begin{array}{c}\text { Initial crack } \\
\text { length }(\mathrm{mm})\end{array}$ & $\begin{array}{c}\varepsilon_{\mathrm{cr}} \text { at Point } 1 \\
\left(10^{-6}\right)\end{array}$ & $\begin{array}{c}\text { COD at Point } \\
2(\mu \mathrm{m})\end{array}$ & $\begin{array}{c}\text { Jump ing } \\
\text { strain, } \Delta \varepsilon\left(10^{-6}\right)\end{array}$ & $\begin{array}{c}\text { Critical energy } \\
\text { release rate } \\
\left(\mathrm{J} / \mathrm{m}^{2}\right)\end{array}$ \\
\hline INCONEL 738 & 2.0 & 4813 & 21 & 7174 & 36.5 \\
INCONEL 738 & 2.0 & 3553 & 28 & 4632 & 53.1 \\
INCONEL 738 & 5.0 & 4815 & 15 & 7176 & 30 \\
INCONEL 738 & 5.0 & 2584 & 12 & 2584 & 30 \\
INCONEL 738 & 0.0 & 4825 & 18 & 7165 & 41.4 \\
\hline SUS 304 & 5.0 & 1450 & 22 & 1599 & 36.1 \\
SUS 304 & 5.0 & 5059 & 25 & 8328 & 71.9 \\
\hline
\end{tabular}

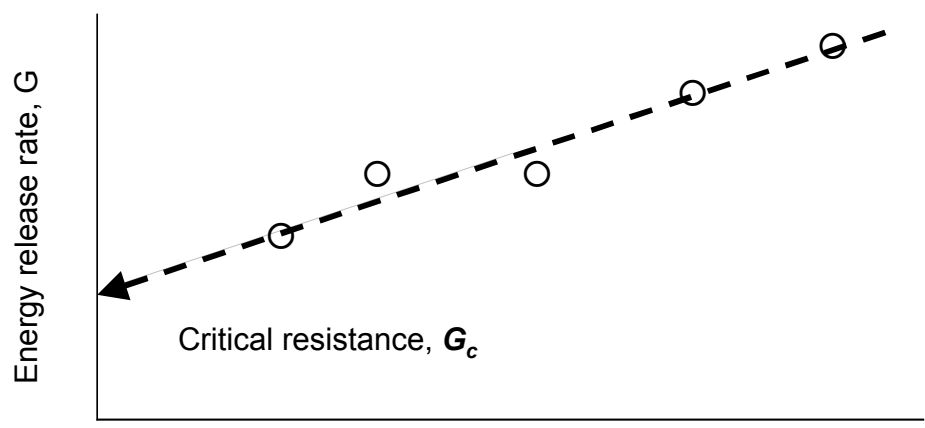

Amount of interface crack advance, $\Delta l$

Fig. 7 Schematic illustration to estimate the resistance to decohesion crack nucleation by extrapolating method of the stable crack growth curve. 


\section{Summary}

A new testing method to evaluate adhesion strength of ceramic top coat in TBCs has been proposed, developing a new type of ring shape specimen.

(1) A new testing method to evaluate adhesion strength has been proposed. In the method a delamination behavior of top coat was successfully reproduced, associating with a buckling mode that was similar to that frequently observed in actual TBC system.

(2) An procedure to experimentally evaluate energy release rate with delamination crack growth has been derived for the proposed specimen.

(3) The testing method provided a reasonable adhesion strength in terms of energy criterion, which almost agreed with the values measured by other researchers employing different type of testing method. In addition, the proposed method has many advantages compared with the traditional methods. One of them is that the method enables us the evaluation without direct contact with top coat, with no adhesives and with in-situ residual stress. Thus, the proposed method is expected to be a new testing method.

\section{Acknowledgement}

Financial supports by the Grain-in-Aid for Scientific Research by JSPS (No. 21246022) is greatly acknowledged.

\section{References}

(1) Miller, R. A., Oxidation Based Model for Thermal Barrier Coating Life, J. American . Ceramics Soc., Vol. 67 (1984), pp. 517-521.

(2) National Research Council, Coatings for high temperature structural materials -Trends and opportunities-, National Academy Press, Washington D.C., (1996).

(3) Seth, B. B., Superalloys: The utility gas turbine perspective, Superalloys 2000, ed. T. Pollock et al., TMS, Warrendale, PA (2000), pp. 3-12.

(4) Schneider, and K., Grunling, H. W., Influence of coatings and hot corrosion on the fatigue behavior of Ni-based superalloys, Thin Solid Films, Vol. 84 (1981), pp. 29-36.

(5) Sudrashan, T. S., (Ed.), Surfac Modification Technologies III, TMS, Warrendale, PA, (1990).

(6) Okazaki, M., The Potential for The Improvement of High Performance Thermal Barrier Coatings, Mater. Research Soc. Int., Vol. 55 (2003), pp. 3-10.

(7) ASTM Standard Test Method for Adhesion or Cohesion Strength of Thermal Spray Coatings, C633-01 (2008) ASTM.

(8) Hutchinson, J. W., Metal-Ceramic Interfaces, ed. By M. Ruhle, A. G. Evans, M. F. Ashby J. P. Hirth, Pergamon press, London (1990), pp. 295-306.

(9) Chai, H., Babcock, C. D., and Knauss, G, One dimensional Modelling of Failure in Laminated Plates by Delamination Buckling, Int. J. Solid \& Structures, Vol. 17, No.11 (1981), pp.10691083.

(10) Evans, A. G., and Hutchinson, J. W., On the Mechanics of Delamination and Spaling in compressed Films, Int. J. Solid \& Structures, Vol.20, No.5 (1984), pp. 455-466.

(11) Subcommittee on Superalloys and Coatings, Phase II Activities: -Basic physical properties of air plasma sprayed thermal barrier coating-", ed. by M. Okazaki, The Society of Materials Science, Japan (2005), ISBN 4-901381-28-8.

(12) Howard, S. J., Tsui, Y. C., and Clyne, T. W., The Effect of Residual Stresses on the Debonding of Coating, Acta Mertall. Mater., Vol. 42, No. 8 (1994), pp.2823-2836.

(13) Yamazaki, Y., Schmidt, A., and Scholz, A., The Determination of the Delamination Resistance in Thermal Barrioer Coating System by Four-Point Bending Tests, Surface and Coating Technology, Vol. 201 (2006), pp. 744-754.

(14) Osakabe, M., Yamagishi, S., and Okazaki, M., Residual Stress Measurement of CeramicTop Coat by Stress Relief Method, Proceedings of 46-th Symposium on High Temperature Strength of Materials, The Soc. Mater. Sci., (2008), pp. 53-57

(15) ASTM E813-89E01, Test Method for JIC, A Measure of Fracture Toughness (1997) ASTM. 